\title{
The acquisition and extinction of peer imitation in children' ${ }^{2}$
}

Barbara S. Clark DALHOUSIE UNIVERSITY

\begin{abstract}
Abstraet
A method is described for studying systematically the acquisition and extinction of peer imitation in children. Response consequences to a peer model were varied. Imitation of a reinforced model increased significantly. A strong tendency to counter-imitate a nonreinforced model was observed. Counter-imitation extinguished readily.
\end{abstract}

\section{Problem}

Children acquire a good deal of behavior through imitation of the behavior of peers. Since Miller \& Dollard's (1941) demonstration that imitative behavior in children can be instrumentally conditioned, several studies have shown that the behavior of adult models (Bandura \& Kupers, 1963; Jakubczak \& Walters, 1959; Rosenblith, 1959), filmed child models (Bandura et al, 1963), and adult models who interact positively with children (Bandura \& Huston, 1961) affect the frequency of children's imitative behavior. Little is known about the specific conditions under which the behaviors of a peer become discriminative stimuli for further imitative behavior and how imitative behaviors are maintained, extended or diminished.

There is some evidence that peer models who are rewarded are more readily imitated than those who are punished or not rewarded. (Kanareff \& Lanzetta, 1960; Shwartz, 1953; Walters et al, 1963.) The evidence suggests that in examining the acquisition of imitation it is relevant to determine further some of the effects of immediate response-contingent consequences to a peer model.

The experiment reported here measured the effects of continuous reinforcement and non-reinforcement of a peer model on the acquisition and extinction of imitative behavior. A method was developed which consists of a simple two choice discrimination which enables the $\mathrm{S}$ to counter-imitate as well as non-imitate. The response is discrete, easily observed, capable of innumerable repetitions, has minimal emotional complications and can be reliably measured.

\section{Method}

The Ss were 18 boys between the ages of 9 and 11 years, randomly assigned to two groups, one with a reinforced model $(R)$ and one with a non-reinforced model (NR). Two Ss were eliminated from the $R$ group because of apparatus failure leaving seven in the $R$ group and nine in the NR group. Median age was 10 years 11 months for the $\mathrm{R}$ group and 10 years 3 months for the NR group. Each $\mathrm{S}$ was paired with a model of his own age and school grade whom he did not know. Five models ranging in age from 9 to 11 years were employed as confederates of the experimenter.

Two white consoles, each with a session light, feedback lights and plastic covered reinforcement tray were mounted side by side on a wall. Each console had two plexiglass push buttons mounted horizontally parallel which activated microswitches.

Cues to the model were projected by a digital display unit through the left disc on the model's panel. Models were cued to respond in a fixed random left-right pattern.

Stimuli were programmed and responses recorded by a system of switching circuits housed in an adjacent control room. Reinforcements were delivered by means of Gerbrands universal feeders mounted in the control room. All responses were recorded on a Gerbrands 6-channel event recorder. Model responses and $\mathrm{S}$ reinforcements were recorded on digital counters. Sessions were begun by a door switch activating a session light when $\mathrm{E}$ left the room, and terminated by E switching off the session light in the control room. A small fan in the experimental chamber was used to mask apparatus noise.

Reinforcements were tokens which were exchanged for pennies at the end of the session. One token was worth one-half penny. Delivery of reinforcements was accompanied by a soft buzzing sound of the feeder and a light illuminating the tray for $1 \mathrm{sec}$.

The $\mathrm{S}$ and model were brought in as soon as they arrived, giving them no opportunity for conversation. Conversation was not permitted until the session ended. They were seated at the consoles and the following instructions (similar to those of Miller \& Dollard, 1941) were given:

"We are going to play a game. It is in two parts. First, I want you to practice pressing these buttons. Press them one at a time. We will take turns. Will you (model) please go first, press one button, then you (S) press one. You may begin when the light goes on and keep on until it goes off. Then I will tell you what to do next. Please don't talk until it is all over. Any questions?"

Block 1. Fifty unreinforced trials followed to determine the initial tendency to imitate, and characteristic patterns of responding. When these were completed $\mathrm{E}$ entered and gave the following instructions:

"Now we will do the same thing. This time when you press the button, if you are correct a token will fall here. It is worth a half penny and can be cashed in when 
we are finished. Any questions? No talking. You may begin when the light goes on."

Block 2. Fifty trials followed in which Ss were reinforced for every imitative response while models were either reinforced for every response (R group) or never reinforced (NR group).

$\mathrm{Block} 3$. Without further instructions, 50 extinction trials followed with no reinforcements to either model or $\mathrm{S}$.

Responses matching the model's response are imitative while responses opposite to those of the model are counter-imitative. A chance level is 25 out of 50 trials.

\section{Results}

During the first block of trials both groups imitated at a level slightly and insignificantly below chance. The two groups did not differ significantly in this respect.

During the conditioning period (block 2) the $\mathrm{R}$ group showed a significant increase in imitative responses, yielding a $t$ of $5.961(p<.001)$. In contrast, the NR group showed a tendency to counter-imitate. This did not represent a significant change from their slightly below chance level of block 1 but was significantly below the chance level. During the second block of trials differences in imitative responding between groups $R$ and NR were significant $(t=3.797 ; p<.01)$. In extinction, imitative responding in the NR group returned to its block 1 level.

\section{Diseussion}

There are clear differences in imitative responding as a function of response consequences to the model. Reinforcement of the model yielded a significant increase in imitation. With a non-reinforced model Ss also showed a tendency to respond with reference to the model, but the tendency was to counter-imitate, despite the fact that this decreased their reinforcements. This suggests that the observation of negative consequences to the model may be an effect of some power.

Although the effects of reinforcements to the model are quite clearcut, there is considerable intra-subject variability in imitative responses. Runs of seven or eight imitative responses followed by non-imitative responses illustrate the dangers of employing a criterion of imitation as lenient as the five consecutive imitative responses used by Miller \& Dollard (1941). Intersubject variability suggests that other factors influence the development of cue properties in the model. For example, there may be differences in the effective value of the reinforcer among Ss. One would hardly expect that models become cues for every child in the same way. Some children, for example, might require a corrective situation where non-imitation is negatively reinforced. The search for and recording of these differences is the kind of information required to answer questions about the acquisition of imitative processes.

The present methodology would seem to be a flexible way of studying these effects further. It is possible to obtain an initial pattern of responding for each $\mathrm{S}$ and use it as a baseline for comparison of individual patterns of acquisition. The method also provides the $\mathrm{S}$ with the opportunity to display counter-imitative behavior. With the use of the minimal social situation, characteristics of the model may be varied systematically.

\section{helerences}

BANDURA, A., \& HUSTON, ALETHA C. Identification as a process of incidental learning. J. abnorm. soc. Psychol., 1961, 63, 311-318.

BANDURA, A., \& KUPERS, CAROL J. The transmission of patterns of self reinforcement through modeling. J. abnorm. soc. Psychol., $1964,69,1-9$.

BANDURA, A., ROSS, DOROTHEA, \& ROSS, SHIELA A. Imitation of film-mediated aggressive models. J. abnorm. soc. Psychol., 1963, $66,3-11$.

JAKUBCZAK, L. F., \& WALTERS, R.H. Suggestibility as dependency behavior. J. abnorm. soc. Psychol., 1959, 59, 102-107.

KANAREFF, VERA T., \& LANZETTA, J。 T. Effects of success failure experience and probability of reinforcement upon the acquisiton and extinction of an imitative response. Psychol. Rep., 1960, 7, 151-156.

MILLER, N。E., \& DOLLARD, J. Social learning and imitation. New Haven: Yale University Press, 1941.

ROSENBLITH, JUDY F. Learning by imitation in kindergarten children. Child Developm., 1959, 30, 69-80.

SHWARTZ, N. An experimental study of imitation. The effects of reward and age. Senior honors thesis, Radcliffe College, 1953.

WALTERS, R。H. LEAT, MARION, \& MEZEL, L. Response inhibition and disinhibition through empathetic learning. Canad. J. Psychol., $1963,16,235-243$.

\section{Notes}

1. The author is grateful for the cooperation of Dr. Maurice Keating, Superintendent of the Halifax Schools, Mr. Laurie Black, principal of Le Marchant St. School, and Mr. Gerald Mosher, principal of Gorsebrook School.

2. This research was supported by a grant from the Research Develpment Fund of Dalhousie University. 